\title{
Do we really need routine drainage after laparoscopic adrenalectomy and splenectomy?
}

\author{
Piotr Major, Maciej Matłok, Michał Pędziwiatr, Andrzej Budzyński \\ $2^{\text {nd }}$ Department of General Surgery, Medical College, Jagiellonian University, Krakow, Poland
}

Videosurgery and Other Miniinvasive Techniques 2012; 7 (1): 33-39 DOI: 10.5114/wiitm.2011.25610

\begin{abstract}
Introduction: Not only did the introduction of laparoscopy not dispel the controversy over routine drainage after uncomplicated surgery, but paradoxically it contributed to enlivening the debate on the issue.

Aim: To determine the usefulness of operative site drainage after "clean", uncomplicated laparoscopic surgery such as splenectomy or adrenalectomy.

Material and methods: One hundred and seventy-six participants (female : male $114: 62$ ) operated on in our centre between Jan 2008 and Nov 2010 were included in the prospective study. Adrenalectomy was performed in 122 patients and splenectomy in 54. In some patients no drains were left after the procedure, while the others had drainage employed. The incidence and character of post-operational complications, the necessity of repeat surgery and the length of the hospital stay were analysed.

Results: In 112 patients (63.6\%) the drain was inserted in the operational field, while in the remaining 64 (36.4\%) it was not. Out of the whole series of 112 patients with drainage used, complications were observed in 6 cases (5.36\%) while in the group of patients without drainage they appeared in $2(3.12 \%)$ of those operated on ( $p<0.05)$. Infectious complications were observed more often in the series with drainage (3.57\% vs. $0 \%, p<0.05)$. The hospital stay in patients with drainage was statistically significantly longer than in patients without.

Conclusions: Based on the study, no justification for routine drainage after scheduled, uncomplicated laparoscopic adrenalectomy and splenectomy was found. The decision whether to leave a drain should be made for every patient individually.
\end{abstract}

Key words: laparoscopic adrenalectomy, laparoscopic splenectomy, drainage, laparoscopy.

\section{Introduction}

So far there have been no unambiguous, commonly accepted rules of operative field drainage. The main concerns are connected with basic issues does it need to be used at all? If yes, in what situations? How long should it last? The majority of the presented opinions are based on no solid scientific evidence, and the drainage of the operative field results from single observations, surgical tradition and habits or other, similar motives. For that reason considerable differences exist between surgeons, centres or even countries. Previous opinions on operative field drainage are mostly based on laparoscopic cholecystectomy. A different aspect of the issue emerged in the era of interest taken in techniques using access via a single incision to the integument (Single Incision Laparoscopic Surgery - SILS) or natural orifice (Natural Orifice Transluminal Endoscopic Surgery - NOTES), during which drains are not left in the operative field $[1,2]$. Clean surgery, without ali- 
mentary iatrogenic perforation, such as removal of the adrenal glands or spleen, is a good representation for assessment of surgical field drainage usefulness in selected laparoscopic procedures.

\section{Aim}

The aim of the study is to assess the usefulness of operative field drainage in "clean", scheduled laparoscopic procedures (adrenalectomy, splenectomy).

\section{Material and methods}

A prospective study was carried out with reference to two different, scheduled laparoscopic procedures, which met the criteria of "clean" surgery according to a four-class wound classification system developed by the American College of Surgeons [3]. The results of adrenal gland removal and spleen excision were analysed.

The patient selection criteria for the trial in the group undergoing laparoscopic splenectomy were:

- haematological diagnosis:

- idiopathic thrombocytopenic purpura (ITP),

- chronic haemolytic anaemia (autoimmune haemolytic or congenital disorders of erythrocyte structure);

- non-Hodgkin lymphoma (NHL);

- a preoperative platelet count of $50000 / \mathrm{ml}$.

The patient selection criteria for the trial in the group undergoing laparoscopic adrenalectomy:

- hormonally active tumours in the adrenal glands (arising from both the cortex and the medulla part) with excessive hormone production confirmed by laboratory investigation;

- tumours without hormone activity, but meeting any of the following criteria:

- size above $4 \mathrm{~cm}$,

- observed tumour enlargement of $1 \mathrm{~cm}$ in a year,

- no specific features of benign adenoma imaging.

Patients who:

- were administered medications influencing blood coagulation (except for prophylactic doses of low molecular weight heparins) in the preoperative period;

- presented with any features of active bacterial infection;

- presented with intraoperative complications in the form of accidental alimentary iatrogenic perforation or injury to the tail of the pancreas;

- were excluded from the trial.
The following cases were also excluded:

- operations where the conversion to open surgery or surgery with laparoscopic assistance (hand-assisted laparoscopic surgery) was required;

- in which blood loss higher than $300 \mathrm{~cm}^{3}$ was observed or there were difficulties in achieving reliable haemostasis necessitating the use of advanced forms of arresting haemorrhage (argon plasma coagulation, local haemostatic agents);

- there was more than one procedure performed simultaneously.

All the patients were operated on in one centre by the same surgical team. In some patients there were no drains inserted in the operative field. The decision was based on the personal conviction of the operator. In the remaining group closed gravitational drains were employed at the site of the organ removal. A polyvinyl chloride $16 \mathrm{~F}$ drainage tube with factory cut holes in the part directed to the peritoneal cavity was brought out through one of the trocar wounds. It was left until the amount of drained fluid was less than $50 \mathrm{~cm}^{3}$ per day.

The following factors were analysed:

- the kind and frequency of complications;

- the proportion of repeated surgeries (including percutaneous drainage);

- the length of hospital stay after the surgery.

All the data were gathered prospectively in Excel database and their analysis took place after the trial period. The results were analysed with the properly selected parametric and non-parametric tests.

Within 3 years' time (from 2008 January to 2010 December) in the $2^{\text {nd }}$ Department of General Surgery of Jagiellonian University Medical College in Krakow 173 laparoscopic adrenalectomies using transperitoneal access and 116 laparoscopic splenectomies were performed. Out of the whole group of 289 patients 176 were eligible for the trial. Among them, 122 underwent adrenal gland removal, and in the remaining 54 splenectomy was performed. The group consisted of 114 women and 64 men. The median age of participants undergoing adrenalectomy was 47.6 (18-78) years, while for patients undergoing splenectomy it was 50.7 (18-76) years.

Hundred and sixty-three patients included in the study had laparoscopy performed using a few trocars (3 or 4) and 13 participants were operated on using a single access trocar - SILS (4 splenectomies, 9 adrenalectomies). The latter were suitable to close without surgical site drainage. 
In 122 patients from the research series with adrenalectomy performed, a hormonally inactive tumour (incidentaloma) and a chromaffinoma were most frequently diagnosed.

In the case of 54 patients selected for laparoscopic splenectomy, idiopathic thrombocytopenic purpura (ITP) and non-Hodgkin lymphoma (NHL) were most commonly diagnosed (Table I). In 112 patients (63.6\%) the drain was inserted in the operative site, while in 64 (36.4\%) it was not. There was no drain left in the case of 49 adrenalectomies and 15 splenectomies (Table II). The groups with and without drainage were compared with regard to age, length of the procedure and intraoperative blood loss.

The splenectomy average operative time was 82.5 (40-240) min, and adrenalectomy median operative time was 76.2 (35-180) min. The blood loss during splenectomy was $45.1(0-250) \mathrm{ml}$ and during adrenal gland removal $36.7(0-200) \mathrm{ml}$ (Table III). In patients with the drain left, the median amount of postoperatively drained fluid was $39.03 \mathrm{ml}$ per day. The average amount of fluid after splenectomy was $39.03 \mathrm{ml}$ per day and after adrenalectomy it was $33 \mathrm{ml}$. The drain was removed after 1.5 days on average. After splenectomy the drain remained in for 1.3 days on average, and after adrenalectomy for 1.37 days.
Table I. Pre-operational diagnosis in patients selected for the study

\begin{tabular}{|llll|}
\hline \multicolumn{1}{|c}{ Adrenalectomy } & \multicolumn{2}{c|}{ Splenectomy } \\
\hline Diagnosis & $n$ & Diagnosis & $n$ \\
\hline Incidentaloma & 48 & ITP & 29 \\
\hline Pheochromocytoma & 34 & NHL & 13 \\
\hline Cushing's syndrome & 21 & Anaemia & 7 \\
\hline Conn's syndrome & 16 & Splenic tumour & 4 \\
\hline Metastasis & 3 & Cyst & 1 \\
\hline Total & 122 & Total & 54 \\
\hline
\end{tabular}

Table II. Number of patients in the respective groups with and without drainage

\begin{tabular}{|lllll|}
\hline & \multicolumn{2}{c}{ Adrenalectomy } & \multicolumn{2}{c|}{ Splenectomy } \\
\cline { 2 - 5 } & $n$ & $\%$ & $n$ & $\%$ \\
\hline Without drainage & 49 & 40.2 & 15 & 27.8 \\
\hline With drainage & 73 & 59.8 & 39 & 72.2 \\
\hline Total & 122 & 100 & 54 & 100 \\
\hline
\end{tabular}

Table III. Age, length of the procedure and blood loss in the respective groups

\begin{tabular}{|c|c|c|c|c|c|c|}
\hline & & & $\begin{array}{l}\text { With } \\
\text { drainage }\end{array}$ & $\begin{array}{l}\text { Without } \\
\text { drainage }\end{array}$ & Total & Value of $p$ \\
\hline \multirow[t]{6}{*}{ Adrenalectomy } & \multirow[t]{2}{*}{ Age [years] } & Average & 45.3 & 50.1 & 47.6 & \multirow[t]{2}{*}{ NS } \\
\hline & & Range & $19-74$ & $18-78$ & $18-78$ & \\
\hline & \multirow{2}{*}{$\begin{array}{l}\text { Length of the } \\
\text { procedure [min] }\end{array}$} & Average & 76 & 76.3 & 76.2 & \multirow[t]{2}{*}{ NS } \\
\hline & & Range & $35-180$ & $40-180$ & $35-180$ & \\
\hline & \multirow[t]{2}{*}{ Blood loss [ml] } & Average & 23.6 & 41.2 & 36.7 & \multirow[t]{2}{*}{ NS } \\
\hline & & Range & $0-200$ & $0-200$ & $0-200$ & \\
\hline \multirow[t]{6}{*}{ Splenectomy } & \multirow[t]{2}{*}{ Age [years] } & Average & 52.6 & 47.1 & 50.7 & \multirow[t]{2}{*}{ NS } \\
\hline & & Range & $20-69$ & $18-76$ & $18-76$ & \\
\hline & \multirow{2}{*}{$\begin{array}{l}\text { Length of the } \\
\text { procedure [min] }\end{array}$} & Average & 75.3 & 84.1 & 82.5 & \multirow[t]{2}{*}{ NS } \\
\hline & & Range & $40-210$ & $60-240$ & $40-240$ & \\
\hline & \multirow[t]{2}{*}{ Blood loss [ml] } & Average & 40 & 52.3 & 45.1 & \multirow[t]{2}{*}{ NS } \\
\hline & & Range & $0-150$ & $50-250$ & $0-250$ & \\
\hline
\end{tabular}




\section{Results}

In 8 (4.54\%) out of 176 cases complications were observed within 30 days following the procedure. Four patients required either repeat surgery or percutaneous drainage, while the remainder were treated non-invasively.

Out of 112 patients with the drain left, 6 cases (5.36\%) were complicated, 2 after adrenalectomy and 4 splenectomy. Two complications (1.78\%) connected with bleeding were observed. In a 72-year-old female patient after adrenalectomy haematoma was detected during a USG examination. Its size did not change despite prolonged drainage. It receded spontaneously 1.5 months after the surgery. In the case of one 60-year-old man after splenectomy, bleeding to the abdominal cavity requiring repeat surgery appeared 1 day after the spleen removal. Bleeding manifested with clinical symptoms and bloody contents of the draining fluid. Four other complications (3.57\%) were infectious. In 2 patients (a 62-year-old woman and a 41-year-old man) an abscess was observed in the removed spleen site. In 1 case repeat surgery was necessary, while in the others percutaneous drainage and antibiotics were sufficient. The $3^{\text {rd }}$ patient was a 33-year-old woman, who came to the hospital on the $7^{\text {th }}$ day after splenectomy with fever (around $38^{\circ} \mathrm{C}$ ) and suspected fluid collection in the removed spleen site. In another 64-year-old female patient after adrenalectomy the postoperative wound became infected, which prolonged its healing. In all the patients blood culture results were negative.

In the series of 64 patients with no drainage used, 2 complications occurred (3.12\%). A 34-year-old patient after SILS required repeat surgery which was decided on the basis of clinical symptoms and USG examination. A 55-year-old man after left-sided adrenalectomy, operated on due to symptomatic
Cushing's syndrome, was readmitted to the hospital department in the long-term postoperative period.

The USG examination combined with diagnostic puncture revealed an organized haematoma (negative microbiological test results). The decision was taken to place the patient on further observation and periodic check-ups.

On the whole the difference in incidence of complications between the groups with and without drainage of operative site (5.36\% vs. $3.13 \%$ ) was significant $(p<0.05)$, similarly to the difference in infectious complications incidence $(3.57 \%$ vs. $0 \%, p<0.05)$ (Table IV). The analysis of complications regarding the organ operated on revealed that in the case of adrenalectomy they occurred in 3 patients (2.5\%), while in laparoscopic splenectomy they occurred in 5 people (9.2\%). The difference was significant at the level of $p<0.001$.

After the surgery, the median length of patients' hospital stay was 3.27 (1 to 24 ) days. In the group without drainage patients were released after 2.48 (2-5) days on average; the median length of hospital stay after splenectomy was 2.73 (2-5) days and after adrenalectomy 2.41 (2-5) days. In the group with post-operational drainage used the length of patients' hospital stay was 3.72 (1 to 24) days on average, the median length of hospital stay after splenectomy was 4.58 (2-24) days and after adrenalectomy 3.26 (1-13) days. The length of hospital stay after the surgery in the whole group with drainage and in relation to individual procedures was significantly longer than in patients without the drain left in the peritoneum (Table V).

\section{Discussion}

The often quoted statement by Theodor Billroth about drainage saving many people's lives is widely

Table IV. Post-operational complications in the respective groups

\begin{tabular}{|llllll|}
\hline Type of complication & $\begin{array}{l}\text { Total } \\
(n=176)\end{array}$ & \multicolumn{2}{c}{ Group } & \multicolumn{2}{c|}{ Treatment } \\
\cline { 2 - 6 } & $\begin{array}{l}\text { Without } \\
\text { drainage } \\
(n=64)\end{array}$ & $\begin{array}{l}\text { With } \\
\text { drainage } \\
(n=112)\end{array}$ & $\begin{array}{l}\text { Surgery or percutaneous } \\
\text { drainage }\end{array}$ & Non-invasive \\
\hline Bleeding & $4(2.27 \%)$ & $2(3.13 \%)$ & $2(1.79 \%)$ & 2 & 2 \\
\hline Infection & $4(2.27 \%)$ & $0(0 \%)$ & $4^{*}(3.57 \%)$ & 2 & 4 \\
\hline Total & $8(4.54 \%)$ & $2(3.125 \%)$ & $6^{*}(5.36 \%)$ & 4 & 2 \\
\hline${ }^{*} p<0.05$ & & & & &
\end{tabular}


Table V. Length of post-operational hospital stay in the respective groups

\begin{tabular}{|lllllll|}
\hline \multirow{2}{*}{ Type of procedure } & \multicolumn{2}{l}{ Without drainage [days] } & \multicolumn{2}{c|}{ With drainage [days] } & Value of $p$ \\
\cline { 2 - 5 } & Average & Range & Average & Range & 0.0002 \\
\hline Adrenalectomy & 2.41 & $2-5$ & 3.26 & $1-13$ & 0.00328 \\
\hline Splenectomy & 2.73 & $2-5$ & 4.58 & $2-24$ & 0.00001 \\
\hline Both & 2.48 & $2-5$ & 3.72 & $1-24$ & \\
\hline Overall average & 3.27 & & & & \\
\hline
\end{tabular}

known. But does it still apply to modern video-surgical procedures? Nowadays, when mini-invasive techniques are commonly used, views on perioperative procedures are divided $[2,4,5]$. The majority of multicentre studies failed as they produced conflicting results [5].

The study prepared by Cochrane Database Systemic Review also did not provide an unequivocal answer for the question whether to leave drains after video-surgery $[6,7]$.

Now, drains are most frequently inserted "just in case" to detect early bleeding, leaky anastomosis or suspicious content leaks. During SILS or NOTES surgery drainage is often left out $[1,2,8]$.

In the case of postoperative bleeding the volume and dynamics of draining blood facilitates a decision about further procedures and possible reoperation. However, here the diagnosis can be made based on clinical symptoms and USG examination, which in the case of abundant bleeding gives a clear image of fluid build-up within the abdominal cavity [9-13].

Four patients in the trial group presented with bleeding complications, 2 of them being after splenectomy. In the first one the volume of bloody contents drainage minimally exceeded $200 \mathrm{ml}$, while in the second there was no drain left. In both cases the decision about repeat surgery was made on the basis of oligovolaemic clinical symptoms and the presence of fluid in the abdominal cavity visible in the USG images.

In the other 2 (one with drainage, one without) haematoma in the site of adrenal gland removal receded after non-invasive treatment. Infectious complications constitute a different issue. They may result from the drain left in the operative field as it is not only a passage to remove the contents from the abdominal cavity, but also a potential source of infection [10].
Attention is also paid to the infectious complications connected with the inflammatory reaction induced by the drain. In 1962 Myers described a "drain fever syndrome" which is basically fever with no accompanying symptoms of infection in patients with post-operational drainage. The clinical manifestation disappears after the drain's removal [14].

Infectious complications were observed in 4 patients. In all of them operative field drainage was used after spleen removal. They included 2 cases of abscesses - one was drained with percutaneous drainage, and the other surgically. In the 2 remaining cases antibiotics turned out to be a successful and sufficient method of treatment.

In the case of infectious complications there was no higher volume of drainage from the abdominal cavity observed in patients, and the diagnosis was made on the basis of clinical symptoms and USG examination. All the infectious complications appeared in 4 out of 39 patients who had drainage after splenectomy performed. No single complication of such sort took place in 15 patients with no drain left after spleen removal. Post-operational infection was not noted in any cases of adrenalectomy with or without drainage. Similar results were presented by K.S. Gurusamy and the Cochrane Review research team regarding cholecystectomy and hernia surgery $[6,7]$. It is also worth paying attention to another well-known phenomenon of frequent infectious complications after splenectomy [15]. Although our trial concerning complications after splenectomy includes a small group of participants, it may shed new light on causes of post-operational, infectious complications.

According to Julio and Ishikawa's research the length of hospital stay is shorter when drainage is abandoned [16-18]. Our study also confirmed the shorter hospital stay of patients without drainage. 
On average they were released 1.5 days earlier than those who had drains inserted.

It is believed that the presence of drains is connected with increased abdominal pain in the postoperational period, and the majority of patients notice considerable improvement and diminished ailment after their removal [19]. Other studies indicate that drainage after laparoscopic procedures reduces pain in the shoulders and back caused by subphrenic build-up of $\mathrm{CO}_{2}$ used to create pneumoperitoneum [20]. Additionally, patients with drainage complain about post-operational nausea and vomiting less frequently. Despite that, the routine use of drainage is inadvisable to remove the collected gas in the abdominal cavity in order to decrease pain [21-23]. Previous studies regarding the usefulness of drainage are mostly connected with laparoscopic cholecystectomy. Similarly to our experiences, there were no differences in incidence of bleeding complications observed between groups - with and without drainage [24, 25]. This suggests that drainage does not protect against a defective surgical technique, including bad haemostasis [26].

It is necessary to highlight the fact that a selected group of participants was included in the study. The patients were free of coagulation system disorders, active infection, alimentary iatrogenic perforation, spleen damage, impeded intra-operative haemostasis or substantial blood loss.

Although it was a selected series, it constituted the majority among patients undergoing adrenalectomy or splenectomy. The decision whether to use drainage or not was made by the surgical team and evolved with time and gained experience. In spite of that critical observation we believe that there was no justification found for routine drainage after "clean", uncomplicated laparoscopic adrenalectomy. It was observed that drainage does not prevent complications or allow for their earlier recognition.

Bleeding complications were diagnosed on the basis of clinical picture and USG, not on the volume and dynamics of the draining fluid. That is why we think that routine drainage after adrenalectomy is not necessary. Our observations concerning "clean", uncomplicated splenectomy are similar. Here also, in the case of bloody complications, we made a decision about further procedures on the basis of the clinical picture and imaging examination (USG), not on the volume of drainage.
Particular attention must be paid to the fact that all infectious complications occurred in patients with drainage in the surgical site. The advisability of routine drainage of the operative site after splenectomy is rendered questionable by this observation.

To sum up, on the basis of the study no justification for routine drainage after scheduled, uncomplicated laparoscopic adrenalectomy and splenectomy was found. The decision whether to leave a drain should be made for every patient individually. The present work certainly does not exhaust the topic completely, and further studies could be of help to solve still controversial issues.

\section{References}

1. Michalik M, Frask A, Orłowski M. NOTES - Natural Oriface Transluminal Endoscopic Surgery. Videosurgery and Other Miniinvasive Techniques 2007; 2: 98-102.

2. Michalik M, Orłowski M, Frask A, et al. NOTES cholecystectomy the first experience in Poland. Videosurgery and Other Miniinvasive Techniques 2009; 4: 42-5.

3. Lippincott JB. American College of Surgeons Committee on Control of Surgical Infections. Manual on control of infection in surgical patients. $2^{\text {nd }}$ ed. Philadelphia 1984.

4. Kot M, Głuszek S, Matykiewicz J, et al. Laparoscopic cholecystectomy - is it safe operation method? Our experiences. Videosurgery and Other Miniinvasive Techniques 2006; 1: 113-20.

5. Askew J. A survey of the current surgical treatment of gallstones in Queensland. Aust N Z J Surg 2005; 75: 1086-9.

6. Gurusamy K, Samraj K, Mullerat P, et al. Routine abdominal drainage for uncomplicated laparoscopic cholecystectomy (Review). Cochrane Database Syst Rev 2007; 3: CD006004.

7. Gurusamy K, Samraj K. Wound drains after incisional hernia repair (Review). Cochrane Database Syst Rev 2007; 3 : CD005570.

8. Cywiński, Kuzdak K, Kołomecki K. One-incision approach (SILS) for retroperitoneal videoscopic adrenalectomy. Videosurgery and Other Miniinvasive Techniques 2010; 5: 70-1.

9. Williams A. Cholecystectomy: ironmasters and eggheads. J Roy Soc Med 1980; 81: 560-1.

10. Budd D, Cochran R, Fouty W. Cholecystectomy with and without drainage. A randomized study of 300 patient. Am J Surg 1982; 143: 307-10

11. Goldberg I, Goldberg J, Liechty R, et al. Cholecystectomy with and without drainage. Am J Surg 1975; 130: 29-32.

12. Elboim C, Goldman L, Hann L, et al. Significance of post-cholecystectomy subhepatic fluid collection. Ann Surg 1983; 198: 137-41.

13. Hoffman J, Lorentzen M. Drainage after cholecystectomy. $\mathrm{Br}$ J Surg 1985; 72: 423-7.

14. Myers M. Drain fever, complication of drainage after cholecystectomy. Surgery 1962; 52: 314-7.

15. Budzyński A. Ryzyko infekcji po usunięciu śledziony, źródła hemocyty, polipeptydów o działaniu bakteriobójczym. Rozprawa 
habilitacyjna. Wydawnictwo Medycyna Praktyczna, Kraków 2007

16. Julio A, Diez M, Pujato R, et al. The need of drainage after cholecystectomy. HBP Surgery 1990; 3: 5-10.

17. Georgiou C, Demetriou N, Pallaris T. Is the routine use of drainage after elective laparoscopic cholecystectomy justified? A randomized trial. J Laparoendosc Adv Surg Tech A 2011; 21: 119-23.

18. Ishikawa K, Matsumata T, Kishihara F, et al. Laparoscopic cholecystectomy with and without abdominal prophylactic drainage. Digest Endosc 2011; 23: 153-6.

19. Hawasli A, Brown E. The effects of drains in laparoscopic cholecystectomy. J Laparoendosc Surg 1994; 4: 393-8.

20. Jorgensen J, Gillies R, Hunt D. A simple and effective way to reduce postoperative pain after laparoscopic cholecystectomy. Aust N Z J Surg 1995; 65: 466-9.

21. Nursal T, Sedat Y, Akin T, et al. Effect of drainage on postoperative nusea, vomiting, and pain after laparoscopic cholecystectomy. Langenbecks Arch Surg 2003; 388: 95-100.

22. Wills V, Hunt D. Pain after laparoscopic cholecystectomy. Br J Surg 2000; 87: 273-84.

23. Hardacre J, Talamini M. Pulmonary and hemodynamic changes during laparoscopy - are they important? Surgery 2000; 17: 241-4.

24. Tzovaras G, Paraskevi L, Fafoulakis F, et al. Is there a role for drain use in elective laparoscopic cholecystectomy? A controlled randomized trial. Am J Surg 2009; 197: 759-63.

25. Druart M, Fetelian D, Engelman E. Elective cholecystectomy without drainage and without prophylactic antibiotics. A prospective randomized trial with clinical and bacteriological aspects. Acta Chir Belg 1990; 90: 79-85.

26. Manson R, Keane B, Brendan G. Cholecystectomy is safer without drainage: the results of a prospective, randomised clinical trial. Surgery 1991; 109: 740-6. 